\title{
Double blind, placebo controlled trial of metronidazole in Crohn's disease
}

\author{
L Sutherland, J Singleton, J Sessions, S Hanauer, E Krawitt, G Rankin, R Summers, \\ H Mekhjian, N Greenberger, M Kelly, J Levine, A Thomson, E Alpert, E Prokipchuk
}

\begin{abstract}
A double blind study compared the efficacy of metronidazole in two doses $(20 \mathrm{mg} / \mathrm{kg}, 10 \mathrm{mg}$ ) kg) with placebo in patients with Crohn's disease. One hundred and five patients participated but only 56 completed the 16 week study - 21 were withdrawn for deterioration of symptoms, 17 for adverse experiences, and 11 for protocol violation. Significant improvement in disease activity as measured by the Crohn's disease activity index (metronidazole $20 \mathrm{mg}$ ) kg, 97 units; metronidazole $10 \mathrm{mg} / \mathrm{kg}$, 67 units; placebo -1 unit, $p=0.002$ ) and serum orosomucoid (metronidazole $20 \mathrm{mg} / \mathrm{kg} /$ day, 49; 10 $\mathrm{mg} / \mathrm{kg} /$ day, 38; placebo, $-9, \mathrm{p}=0.001)$ ) were detected. Changes in $\mathrm{C}$ reactive protein concentrations did not achieve significance when all three groups were considered but were significant when all metronidazole treated patients were grouped and compared with the placebo treated patients $(0.8 v-0.9, \mathrm{p}<0.05)$. Although patients receiving metronidazole 20 $\mathrm{mg} / \mathrm{kg} /$ day had a greater improvement in disease activity than those receiving $10 \mathrm{mg} / \mathrm{kg} /$ day (difference 30 units ( $95 \%$ confidence intervals -27-87), the small sample size may have precluded the detection of statistical significance. Preliminary analysis suggests that metronidazole was more effective in patients with disease confined to the large intestine or affecting both small and large bowel than in those with small bowel disease only. There were no differences in remission rates between metronidazole and placebo treated patients. We conclude that metronidazole warrants further assessment in the treatment of patients with active Crohn's disease.
\end{abstract}

L Sutherland

J Singleton

S Hanauer

E Krawitt

G Rankin

R Summers

H Mekhiian

N Greenberger

M Kelly

$J$ Levine

A Thomson

E Alpert

E Prokipchuk

Correspondence to:

Dr L R Sutherland, Rm 1717

Dr 330 Hospital Drive, $N W$

3330 Hospital Drive, NW T2N 4N1.

Accepted for publication 19 November 1990 efficacy and the appropriate dose required ${ }^{2-6}$ This multicentre trial was initiated to assess the efficacy of metronidazole in the treatment of Crohn's disease and to determine whether its effectiveness was dose related. Although early closure of the trial did not allow sufficient patient entry to achieve all of the stated goals, enough patients were enrolled to provide an assessment of efficacy.

\section{Methods}

This double blind placebo controlled multicentre trial was conducted between October 1983 and January 1986. It assessed the efficacy of two regimens of metronidazole $-20 \mathrm{mg} / \mathrm{kg} / \mathrm{day}$ and $10 \mathrm{mg} / \mathrm{kg} / \mathrm{day})$ - in the treatment of Crohn's disease. Thirteen centres (10 American, three Canadian) participated. The protocol was approved by the institutional review boards at each centre.

Patients were eligible for enrolment if their disease activity, as measured by the Crohn's disease activity index ${ }^{7}$ score, was greater than 180 and less than 450 . Patients had evidence of Crohn's disease documented either radiologically $^{8}$ or endoscopically. ${ }^{9}$ The extent of disease was determined either at the time of admission or by radiological or endoscopic procedures carried out within the previous year. Patients who had previously been treated for Crohn's disease were eligible for inclusion in the trial but all medical treatment was stopped before entry (steroids, two months; metronidazole, four weeks; sulphasalazine, two weeks). Patients with acute ileitis or perianal disease with no disease evident above the rectum were excluded. Patients who were considered to need surgery in the near future were not enrolled. Finally, women of childbearing age who were not using an effective form of birth control (oral contraceptives, intrauterine devices) were excluded.

Patients were randomly assigned, in the order in which they were enrolled, to receive either metronidazole $(20 \mathrm{mg} / \mathrm{kg}$ or $10 \mathrm{mg} / \mathrm{kg})$ or placebo, dispensed as two $250 \mathrm{mg}$ tablets three times a day. Patients were assessed at baseline and at weeks two, four, eight, 12, and 16. At each visit the Crohn's disease activity index score was calculated and serum was drawn for orosomucoid and $C$ reactive protein determination. Patient compliance was assessed through pill counts and determination of serum metronidazole concentrations.

Patients could be withdrawn from the study if the activity score was greater than 450 at any time during the study or if the investigator was of the opinion that the patient's condition was worsening. 


\section{STATISTICAL METHODS}

The primary analysis was based on changes in the severity of the subject's illness as determined by the Crohn's disease activity index, measured at study entry and termination. Analysis of activity index subcomponents was also performed using analysis of variance (ANOVA) for continuous variables (number of stools, abdominal pain, general wellbeing, haematocrit and weight deviation) and $\chi^{2}$ testing for changes in categorical variables (number of complications, taking opiate antidiarrheal medications, presence of an abdominal mass). Using the intent to treat rule, all patients who received at least one dose of study medication were included. An ANOVA of the change in Crohn's disease activity index score (final minus initial) was performed with treatment and study centre as factors. In some centres insufficient patients were enrolled to carry out this analysis. When an overall test for treatment group differences was found to be significant $(p<0.05)$ the Bonferroni method of adjusting for multiple comparisons was used to make specific treatment comparisons.

For purposes of comparison with previous studies, an arbitrary definition of remission was taken as the achievement of an activity index of less than 150. This criterion was not used to judge the success of active drug regimens as it had not been defined at the onset of the study as a response criterion.

Secondary assessments included determination of changes in plasma orosomucoid and $\mathrm{C}$ reactive protein values. In an attempt to examine further the effect of metronidazole in Crohn's disease, the two active treatment groups were combined and compared with the placebo group to examine the effect of metronidazole when stratified by disease location.

TABLE I Demographic characteristics of the 99 patients who participated in the trial. The three groups are comparable, although placebo treated patients tended to have lower disease activity indices (CDAI) on entry to the trial compared with actively treated patients

\begin{tabular}{lccc}
\hline & $\begin{array}{l}\text { Metronidazole } \\
(10 \mathrm{mg} / \mathrm{kg})\end{array}$ & $\begin{array}{l}\text { Metronidazole } \\
(20 \mathrm{mg} / \mathrm{kg})\end{array}$ & Placebo \\
\hline No enroled & 33 & 30 & 36 \\
Disease location: & $15(46)$ & $9(30)$ & $16(45)$ \\
$\quad$ Small intestine (\%) & $14(42)$ & $17(57)$ & $16(45)$ \\
$\quad$ Smal/large intestine & $4(12)$ & $4(13)$ & $4(10)$ \\
$\quad$ Large intestine (\%) & $14(42)$ & $10(33)$ & $12(33)$ \\
Previous treatment: & $17(52)$ & $20(68)$ & $25(69)$ \\
$\quad$ Surgery (\%) & $26(79)$ & $21(70)$ & $26(72)$ \\
$\quad$ Steroid use (\%) & $282(67)$ & $313(71)$ & $280(61)$ \\
Entry data (mean (SD)) & $137(45)$ & $137(56)$ & $121(59)$ \\
$\quad$ CDAI & $2 \cdot 8(3 \cdot 0)$ & $2 \cdot 6(3 \cdot 0)$ & $1 \cdot 7(1 \cdot 7)$ \\
$\quad$ Orosomucoid & & &
\end{tabular}

Analysis of variance, $\mathrm{p}<0 \cdot 10$.

TABLE II Length of time patients remained in the study and reason for premature termination of all treatment groups. There are no significant differences between groups

\begin{tabular}{lllc}
\hline & $\begin{array}{l}\text { Metronidazole } \\
(10 \mathrm{mg} / \mathrm{kg})\end{array}$ & $\begin{array}{l}\text { Metronidazole } \\
(20 \mathrm{mg} / \mathrm{kg})\end{array}$ & Placebo \\
\hline $\begin{array}{l}\text { Time in study (weeks (\%)): } \\
>2\end{array}$ & $32 / 33(97)$ & & \\
$>4$ & $31 / 33(94)$ & $29 / 30(97)$ & $34 / 36(94)$ \\
$>8$ & $27 / 33(82)$ & $27 / 30(90)$ & $28 / 36(78)$ \\
$>12$ & $22 / 33(67)$ & $22 / 30(77)$ & $23 / 36(56)$ \\
$>16$ & $21 / 33(64)$ & $19 / 30(67)$ & $19 / 36(53)$ \\
Reason for stopping: & 4 & 2 & $16 / 36(44)$ \\
$\quad$ Adverse event & 5 & 6 & 8 \\
Worsening disease & 3 & 3 & 10 \\
Protocol violation & 5 & & 2 \\
\hline
\end{tabular}

\section{Results}

PATIENT CHARACTERISTICS (Tables I and II)

One hundred and five subjects entered the study before its premature discontinuation. Six patients were removed from the analysis either because their entry Crohn's disease activity index score was greater than 450 (2) or withdrawal either because of serious side effects (2) or protocol violations (2) prevented calculation of the final score. This report therefore presents the $\mathscr{D}$ results of treatment in 99 patients. The number $\approx$ of patients enrolled per centre ranged from one $\vec{\circ}$ to 17 with $77 \%$ ( 76 of 99 ) drawn from six centres. A $\log$ of patients rejected for entry into the study $\vec{\omega}$ was not kept. Fifty six patients completed the full 16 weeks of the study (Table II). Twenty one patients were withdrawn by the investigators because of either worsening symptoms or lack of improvement (placebo 10, metronidazole 11). Fourteen patients (placebo (8), metronidazole (6)) were withdrawn because of an adverse event (see below). Eight patients (placebo (2), metronidazole (6)) withdrew because of protocol deviations (non-compliance with study medication (5), non-compliance with study visits (1), positive pregnancy test (1), lost to follow up (1)). There were no significant differences either in the number who withdrew or time to withdrawal between all'three groups.

The three treatment groups were comparable in terms of the men:women ratio, age, weight, height, and serum orosomucoid and $\mathrm{C}$ reactive protein values (Table I). Similarly, there were no differences with regard to disease location, previous surgery, and previous medications between treatment groups. Patients who were randomised to placebo tended to have a lower Crohn's disease activity index score on study entry compared with those receiving metronidazole, but the differences did not reach statistical significance.

\section{CROHN'S DISEASE ACTIVITY INDEX (Tables III} and IV and Figure)

The primary measure of efficacy was a change in the activity index score. These changes along with $95 \%$ confidence intervals for each treatment group are shown in Table III for all 99 patients. For patients who withdrew from the study, the final score calculated before discharge was used. As can be seen, there were significant differences in the change in disease activity index score for patients receiving either dose of metronidazole compared with placebo. A higher proportion of patients in the metronidazole groups than in the placebo group finished the trial with a disease activity score below 150 (arbitrarily defined as remission). However, the difference in proportions did not reach statistical significance. Changes in the score were not significant when the two metronidazole treatment groups were compared with each other.

An analysis of change in activity index subcomponents for continuous variables (number of stools a day, abdominal pain, sense of wellbeing, haematocrit, weight) showed only statistically significant changes in severity of abdominal pain for patients receiving metronidazole $20 \mathrm{mg} / \mathrm{kg}$ 


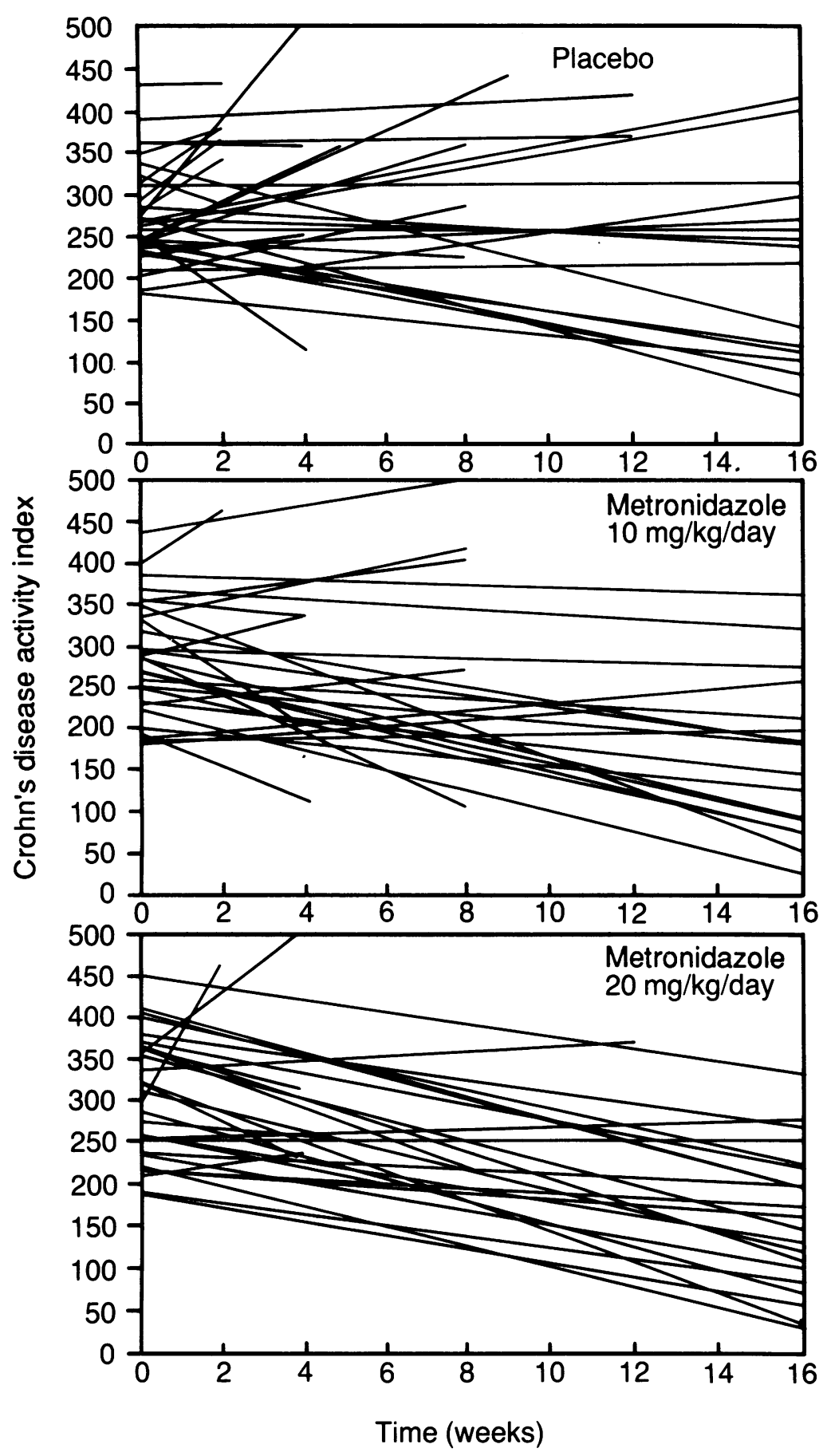

Changes in Crohn's disease activity index (CDAI) for all patients characterised by treatment group and duration in study.

$(\mathrm{p}<0 \cdot 01)$. There was a trend toward improvement in general wellbeing $(p=0.06)$ and haematocrit $(p=0 \cdot 053)$. There were no significant changes in the categorical components of the

TABLE III Changes in outcome measures (entry value-value at time of study completion or withdrawal) with $95 \%$ confidence intervals for all groups. A positive sign indicates improvement, while a negative sign indicates worsening disease. Significant differences in Crohn's disease activity index (CDAI) and orosomucoid value between metronidazole and placebo treated patients were detected

\begin{tabular}{|c|c|c|c|c|}
\hline & $\begin{array}{l}\text { Metronidazole } \\
(10 \mathrm{mg} / \mathrm{kg}) \\
(n=33)\end{array}$ & $\begin{array}{l}\text { Metronidazole } \\
(20 \mathrm{mg} / \mathrm{kg}) \\
(n=30)\end{array}$ & $\begin{array}{l}\begin{array}{l}\text { Placebo } \\
(n=36)\end{array}\end{array}$ & p value \\
\hline $\begin{array}{l}\text { CDAI } \\
\text { Orosomucoid } \\
\text { C reactive protein } \\
\text { Entering remission (\%) }\end{array}$ & $\begin{array}{l}+67(26-108) \\
+38(21-55) \\
0 \cdot 9(-3 \cdot 0-1 \cdot 9) \\
36\end{array}$ & $\begin{array}{l}+97(55-139) \\
+49(20-70 \\
0 \cdot 8(-1 \cdot 0-2 \cdot 7) \\
27\end{array}$ & $\begin{array}{l}-1(-37-45) \\
-9(-23-5) \\
-0 \cdot 9(-1 \cdot 9-0 \cdot 1) \\
25\end{array}$ & $\begin{array}{l}0.002 \\
0 \cdot 001 \\
\text { NS } \\
\text { NS }\end{array}$ \\
\hline
\end{tabular}

activity index (number of complications, use of opiates, presence of abdominal mass) for patients receiving metronidazole compared with placebo treated patients.

In an attempt to define patient groups that might benefit from metronidazole therapy, the two metronidazole groups were combined and compared with placebo and stratified by disease location (Table IV). Significant reductions in activity index scores were found in patients with disease in both small and large intestine and large intestine alone. Although the activity index score fell more in metronidazole treated patients with small bowel disease compared with those receiving a placebo, the difference was not statistically significant. There were no significant differences in response to treatment when patients were stratified by previous surgery or prior use of either sulphasalazine or corticosteroids.

The figure presents graphically the response in Crohn's disease activity index score as well as duration of treatment for all patients who were enrolled in the study. The placebo group can be characterised by the number of early withdrawals, with only a few patients showing a score reduction. The metronidazole groups are characterised by few early withdrawals and a general decline in the activity index score.

Finally, multiple stepwise regression using change in the Crohn's disease activity index as the dependent variable with metronidazole, disease location, previous therapy (corticosteroids, sulphasalazine), and history of previous surgery as independent variables was performed. Use of metronidazole and disease location were both found to influence significantly $(p<0.0003)$ a change in the activity index. Tests for an interaction between treatment group and disease location were suggestive of a relation between the two but did not reach statistical significance (ANOVA, 0.05<p $<0 \cdot 10$ ).

SERUM OROSOMUCOID AND C REACTIVE PROTEIN Mean changes in $\mathrm{C}$ reactive protein and orosomucoid values are shown in Tables III and IV. Evidence of efficacy was again shown. Orosomucoid declined significantly in each treatment group compared with the placebo group. Although the $\mathrm{C}$ reactive protein changes did not achieve initial statistical significance, when all metronidazole patients were combined and compared with patients who received placebo, significant changes were noted.

\section{ADVERSE EVENTS}

There were no significant changes in biochemical assessments in treatment groups during the course of the study. At each visit patients were asked if they had any complaints and were specifically questioned about symptoms of neuropathy (numbness, burning sensation in arms and legs). Fourteen patients were withdrawn because of an adverse event - eight receiving placebo and six metronidazole. One patient on the higher dose of metronidazole had an intestinal perforation while another developed severe thrombocytopenic purpura (both patients were excluded from the final 
TABLE IV Mean change in Crohn's disease activity index (CDAI) (95\% confidence intervals) for all metronidazole treated patients compared with those receiving placebo. A positive sign indicates improvement in the index

\begin{tabular}{llll}
\hline & Metronidazole & Placebo & p value \\
\hline Mean change in CDAI: & & & \\
All patients & $+81(52-110)(\mathrm{n}=63)$ & $-1(-37-35)(\mathrm{n}=36)$ & 0.001 \\
Small intestine & $+86(38-134)(\mathrm{n}=24)$ & $+48(-6-103)(\mathrm{n}=17)$ & NS \\
Small/large intestine & $+60(19-101)(\mathrm{n}=31)$ & $-43(-83--3)(\mathrm{n}=15)$ & 0.005 \\
Large intestine & $+145(26-265)(\mathrm{n}=8)$ & $-61(\mathrm{n}=4)$ & 0.05 \\
\hline
\end{tabular}

Analysis of variance for interaction between treatment and disease location $(0 \cdot 5<\mathrm{p}<0 \cdot 10)$.

analysis). We believe this is the first reported case of thrombocytopenia associated with metronidazole treatment.

Other events included gastrointestinal upset with nausea and vomiting and abdominal pain (placebo (5), metronidazole (4)). Two patients (placebo (1), metronidazole (1)) complained of either hypothesia or paraesthesia. Two placebo treated patients were withdrawn because of either a rash or arthralgia. One patient on metronidazole withdrew because of headaches.

\section{Discussion}

Metronidazole is a nitroimidazole compound originally introduced for the treatment of trichomonas vaginitis. It was first suggested to be effective in the treatment of Crohn's disease by Ursing and Kamme in $1975 .^{2}$ They reported five patients with Crohn's disease, most of whom had large bowel involvement, who responded to up to $20 \mathrm{mg} / \mathrm{kg}$ daily of metronidazole. Allan and Cooke $^{10}$ suggested that it would be of particular benefit to patients with colonic disease in whom diarrhoea was a particular problem.

Following these reports, a series of controlled clinical trials of metronidazole were carried out. In the first, ${ }^{+} 22$ patients participated in a double blind crossover study which assessed $1000 \mathrm{mg}$ of metronidazole daily for two months compared with placebo. No significant differences were detected but the patient population was heterogeneous with many taking sulphasalazine or prednisone concurrently. In a subgroup of six patients with Crohn's colitis, improvement in diarrhoea, abdominal pain, and sense of wellbeing were noted.

In the Swedish cooperative Crohn's disease study, 58 patients participated in a crossover comparison of metronidazole (400 mg bid) and sulphasalazine (1.5 gm bid). Each treatment period lasted four months. Approximately $65 \%$ of patients had either ileocoecal or colonic disease. In the first phase of the trial both treatments were found to be equally effective. Mean Crohn's disease activity index score declined by 149 in the metronidazole treated patients compared with 137 in those receiving sulphasalazine. Twenty five per cent of metronidazole patients achieved a score of $<100$, as did $39 \%$ of those receiving sulphasalazine. Plasma orosomucoid declined in both groups but reached significantly lower values in the metronidazole treted group. In the crossover study, metronidazole was also found to be effective in patients who failed sulphasalazine treatment whereas those who received sulphasalazine having failed with metronidazole did not improve. Based on the crossover data, the authors concluded that metronidazole was slightly more effective than sulphasalazine in the treatment of Crohn's disease.

A third study evaluated a variety of antibodies for treatment of active Crohn's disease. " Seventy two patients were randomly assigned to either metronidazole ( $400 \mathrm{mg}$ bid), cotrimoxazole ( 960 mg bid), metronidazole and cotrimoxazole together, or placebo. After four weeks of treatment no significant differences between the groups could be detected. The groups were mixed in terms of disease location, for example, $50 \%$ of placebo treated patients had colonic disease compared with $28 \%$ of those receiving metronidazole. In addition, the small sample size might have precluded detection of subgroups that would have benefited.

Subsequently, other investigators ${ }^{12-14}$ have suggested that perianal disease can be effectively healed or improved in patients treated with metronidazole at a dosage of $20 \mathrm{mg} / \mathrm{kg} /$ day. These conclusions have never been tested by a controlled double blind trial.

Why should metronidazole be effective in Crohn's disease? Two potential mechanisms of action have been suggested. ${ }^{15}$ Metronidazole has been shown to be an effective broad spectrum antibiotic with impressive action against anaerobic bacteria. Perhaps it either sterilises microabscesses in inflamed tissue or alters gut flora. Metronidazole has also been reported to suppress various aspects of cell mediated immunity, ${ }^{16}$ and in this context it may be functioning as an immunosuppressant rather than as antibiotic.

This study showed that metronidazole was effective in reducing the disease activity as measured by Crohn's disease activity index score. The decline in activity index score was accompanied by a fall in serum orosomucoid as well. Serum C reactive protein concentrations fell, and when all metronidazole treated patients were considered, the decline reached statistical significance. When all metronidazole patients were combined it seemed that the effect was most notable in those who had both small and large bowel disease (mainly ileocoecal). There was also evidence of an effect in the large intestine, but since only 12 patients had disease confined to the colon, this conlusion should be interpreted cautiously. The Swedish study found, as we did, that patients with disease confined to the small intestine did not respond as favourably to treatment. It is not clear whether the benefit seen in patients with disease in both large and small bowel is derived from improvement in the colonic segment alone or in the small bowel as well.

The lack of statistical significance in the difference in proportion of patients in active and placebo treatment groups finishing the trial in 'remission' may reflect the arbitrary definition of remission as an activity index score of less than or equal to 150 . The possibility of a type II $(\beta)$ error cannot be excluded. Nevertheless, as can be seen graphically, more metronidazole treated than placebo treated patients had a decline in score during the study period.

Inferences drawn from the analysis of the 
subcomponents of Crohn's disease activity index should be interpreted with caution as the statistical power of these analyses is low. An improvement in abdominal pain and a trend for improvement in haematocrit, sense of wellbeing, and weight are noteworthy. The study was unable to detect a significant difference in the effectiveness of $10 \mathrm{mg} / \mathrm{kg}$ metronidazole $v 20 \mathrm{mg} /$ $\mathrm{kg}$. Resolution of this issue would require a much larger trial. Calculation of the confidence intervals indicates that a significance difference between the two dosage regimens remains possible but such a difference is not assured.

This study shows, however, that placebo controlled studies remain feasible and do not seem to expose patients to unacceptable risks. The use of a placebo is the probable explanation for the high dropout rate related to worsening of the disease. In most of these cases the patients were withdrawn by their physicians because of a failure to improve clinically rather than a dramatic change in their activity index score. It may have been that either patient or physician suspected that they were receiving a placebo and did not wish to continue in the trial. In this study, 20 of 36 patients randomised to placebo did not complete the trial compared with 23 of the 63 who received active treatment.

Side effects for patients participating in the study were few and reversible. This study was not designed to assess the long term safety of chronic therapy with metronidazole. Although only a few patients receiving metronidazole complained of symptoms of a peripheral neuropathy (as did one patient on placebo), studies of patients taking the medication for more than four months report a prevalence for neuropathy as high as $85 \% .{ }^{17}$ Theoretical concerns remain based on the potential carcinogenic, mutagenic, and teratogenic effects of metronidazole. ${ }^{318}$

In conclusion, metronidazole treatment was associated with declines in the Crohn's disease activity index score and in orosomucoid and $\mathrm{C}$ reactive protein values. Although a low remission rate was encountered, we believe that further evaluation of metronidazole is appropriate.

Authors and institutions where this work was performed: $\mathbf{L} \mathbf{R}$ Sutherland, Division of Gastroenterology, Department of Medicine, University of Calgary; J Singleton, Division of Gastroenterology, Department of Medicine, University of Colorado; enterology, Department of Medicine, University of Colorado;
J Sessions, Division of Gastroenterology, Department of
Medicine, University of North Carolina; S Hanauer, Division of Gastroenterology, Department of Medicine, University of Chicago; E Krastroenterology, Departmen ont; G Rankin, Division of Gastroenterology, Department of Medicine, Cleveland Clinic R Summers, Division of Gastroenterology, Department of Medicine, University of Iowa; $\mathbf{H}$ Mekhiian, Division of Gastroenterology, Department of Medicine, Ohio State University N Greenberger, Division of Gastroenterology, Department of Medicine, University of Kansas; $M$ Kelly, Division of Gastroenterology, Department of Medicine, Dartmouth Hitchcock Medical Centre; J Levine, Division of Gastroenterology, Department of Medicine, University of Colorado; A Thomson, Division of Gastroenterology, Department of Medicine, University of Alberta; E Alpert, Division of Gastroenterology, Department of Medicine, Baylor College of Medicine; and A E Prokipchuk, Medicine, Baylor College of Medicine, and A E Prokipchuk, Division of Gastroenterology, Department of Medicine, Diviversity of Toronto.

The authors acknowledge the support of Drs George Clay Stephen Geis (G D Searle and Co) and Drs R Wildeman and $\mathrm{N}$ McCullough (G D Searle and Co of Canada) as well as the hard work and dedication of our study nurses.

Presented in part at the May 1989 Annual Meeting of the American Gastrointestinal Association, Washington DC, USA

Funded by a grant from G D Searle \& Co, Skokie, Illinois, USA and G D Searle \& Co of Canada, Oakville, Ontario, Canada.

1 Babb RR. The use of metronidazole (Flagyl) in Crohn's disease. F Clin Gastroenterol 1988; 10: 479-81.

2 Ursing B, Kamme G. Metronidazole for Crohn's disease. Lancet 1975; i: 775-7.

3 Mitelman F, Strombedk B, Ursing B. No cytogenetic effect of metronidazole [Letter]. Lancet 1980; i: 1249-50.

4 Blichfeldt P, Blomhoff JP, Myrhe E, Gjone E. Metronidazole in Crohn's disease. Scand $\mathcal{Y}$ Gastroenrerol 1978; 13: 123-7.

5 Ursing B, Alm T, Barany F, et al. A comparative study of metronidazole and sulfasalazine for active Crohn's disease: the cooperative Crohn's disease study in Sweden. II. Result Gastroenterology 1982; 83: 550-62.

6 Benjamin SH, Guarino J, Gordon SJ, Friedman LS. Metronidazole (MET): clinical experience in inflammatory bowe disease (IBD) [Abstract]. Gastroenterology 1987; 92: 1314

7 Best WR, Becktel JM, Singleton JW, Kern FJ Jr. Development of a Crohn's disease activity index: National Cooperative Crohn's disease study. Gastroenterology 1976; 70: 43944.

8 Goldberg HI, Caruthers SB, Nelson JA, Singleton JW. Radiologic findings of the National Cooperative Crohn' Radiologic findings of the National Cooperative
disease study. Gastroenterology 1979; 77: 925-37.

9 Waye J. The role of colonoscopy in the differential diagnosis of inflammatory bowel disease. Gastrointest Endosc 1977; 23 $150-4$

10 Allan RN, Cooke WT. Evaluation of metronidazole in the management of Crohn's disease. Gut 1977; 18: A422.

11 Ambrose NS, Allan RN, Keighley RBM, et al. Antibiotic therapy for treatment in relapse of intestinal Crohn's disease. Dis Colon Rectum 1985; 28: 81-5.

12 Bernstein LH, Frank MS, Brandt LJ, Boley SJ. Healing of perineal Crohn's disease with metronidazole. Gastroenterology 1980; 795: 357-65.

13 Brandt LJ, Bernstein LH, Boley SI, Frank MS. Metronida zole therapy for perineal Crohn's disease: a follow-up study. Gastroenterology 1982; 83: 383-7.

14 Hakobovits J, Schuster MM. Metronidazole therapy for Crohn's disease and associated fistulae. $A m \mathcal{F}$ Gastroenterol 1984; 79: 533-40.

15 Gilat T. Metronidazole in Crohn's disease. Gastroenterolog 1982; 83: 702-4

16 Grove DI, Mahmoud AAF, Warren KS. Suppression of cellmediated immunity by metronidazole. Int Arch Allergy Appl Immunol 1977; 54: 422-7.

17 Duff LF, Daum F, Fisher SE, et al. Peripheral neuropathy in Crohn's disease patients treated with metronidazole. Gastroenterology $1985 ; 88: 681-4$.

18 Mitelman F, Hartley-Asp B, Ursing B. Chromosome aberations and metronidazole [Letter]. Lancet 1976; ii: 802. 